\title{
A vida verdadeira do Sambizanga em tempos de viragem
}

Edimara Lisboa ${ }^{1}$

RESUMO: O filme Sambizanga (1972), de Sarah Maldoror, adaptação da novela A vida verdadeira de Domingos Xavier (1961), de José Luandino Vieira, reapresenta ficcionalmente o entorno de um dos episódios-estopim da luta de libertação de Angola, considerado pelo MPLA o marco inicial da guerra, o ataque à Casa de Reclusão Militar, em Luanda, a 4 de fevereiro de 1961. Neste artigo será discutido o processo de adaptação empregado nesse filme e analisadas possibilidades de sentido oferecidas pela leitura comparada com seu texto-fonte.

ABSTRACT: The movie Sambizanga (1972), by Sarah Maldoror, adaptation of the novel A vida verdadeira de Domingos Xavier (1961), by José Luandino Vieira, shows again, and fictionally, the surroundings of an fuse episode of the luta de libertação de Angola, considered by the MPLA the milestone of war, the attack on the Casa de Reclusão Militar, in Luanda, to February 4, 1961. This article discusses the process of adaptation used in this film and analysed the sense of possibilities offered by comparative reading with this movie literary source.

PALAVRAS-CHAVE: Adaptação; Luandino Vieira; Sarah Maldoror; Luta de libertação de Angola. KEYWORDS: Adaptation; Luandino Vieira; Sarah Maldoror; Luta de libertação de Angola.

O homem colonizado que escreve para seu povo deve, quando utiliza o passado, fazê-lo com o propósito de abrir o futuro, convidar à ação, fundar a esperança. Mas para garantir a esperança é preciso participar, engajar-se.

Frantz Fanon, Os condenados da terra.

O potencial do cinema como instrumento de propaganda, de propagação de ideias e valores, foi desde cedo percebido tanto pelas indústrias (hollywoodiana, bélica, de comércio) como pelos governos (de direita, de esquerda, totalitários, movimentos revolucionários). Expressões como "apoderar-se do cinema", "controlá-lo", "dominá-lo" são de uso recorrente nos primeiros políticos soviéticos, como Leon Trótski, Anatóli Lunatcharski e mesmo Lenin. O Partido Comunista da URSS procurou no cinema um contraponto para os atrativos do álcool, da religião e do jogo, maneira de entreter e simultaneamente educar as massas nos princípios oficiais do regime soviético. "O regime

\footnotetext{
${ }^{1}$ Doutoranda do Programa de Pós-graduação em Estudos Comparados de Literaturas de Língua Portuguesa da FFLCH-USP, com a pesquisa "Estranhas Angélicas: confluências entre Manoel de Oliveira e Lúcio Cardoso".
}

Revista Crioula USP, $\mathrm{n}^{\circ}$ 17, junho de 2016 
pretende se expressar através de cine-jornais. A partir de 1918, estes oferecem uma representação bastante completa da realidade soviética" (FERRO, 1992, p. 27). Em contrapartida, foi esse interesse do Estado pelo cinema que possibilitou o desenvolvimento da escola soviética, cujos grandes cineastas (Eisenstein, Pudovkin, Kulechov, Vertov) realizaram obras de indiscutível valor artístico e articularam teoricamente o fazer cinematográfico, em apontamentos que se tornaram fundamentos clássicos da teoria do cinema.

$\mathrm{Na}$ África de língua portuguesa, esse modelo soviético de cinema foi adotado pela FRELIMO de Samora Machel, em Moçambique, num projeto chamado "Kuxa Kanema”, idealizado em torno da ideia de mostrar Moçambique para os moçambicanos e de despertar uma consciência nacional na população do novo país independente e comunista. Em Angola, o Departamento de Informação e Propaganda do MPLA documentou momentos da guerrilha, mas esses filmes praticamente não circularam. Mesmo tendo sido inspirado, desde o início, nos ideais soviéticos, o MPLA não adotou o cinema como instrumento de propaganda mesmo após a independência.

Podemos especular que isso se deu por conta das disputas partidárias pelo poder. Ao contrário da FRELIMO, o MPLA não conseguiu aglutinar as outras frentes de libertação e acabou por entrar em guerra com a UNITA e a FNLA, num conflito civil que durou até 2002; de modo que, os ideais ideológicos do jovem país independente nunca foram completamente centralizados pelo regime político em exercício. Paradoxalmente, há grande qualidade artística no pouco material fílmico que se propõe cinema angolano de intervenção. Os angolanos Ruy Duarte de Carvalho e António Ole são cineastas mundialmente reconhecidos, seus filmes marcam um cinema de intervenção concretizado devido ao esforço individual e de equipe, apesar da falta de subsídios estatais.

Os primeiros filmes sobre Angola descolados da lógica do colonizador europeu são de Sarah Maldoror, uma das primeiras cineastas mulheres terceiro-mundistas, ${ }^{2}$ e já refletem esse caráter artístico do cinema angolano. Monangambé (1968, 20 min., $35 \mathrm{~mm}$ ) e Sambizanga (1972, $102 \mathrm{~min} ., 35 \mathrm{~mm}$ ) foram inspirados em obras de José Luandino Vieira, respectivamente, o conto "O fato completo de Lucas Matesso" e a novela A vida

\footnotetext{
2 Ainda que essa designação diga respeito a uma escolha pessoal. Francesa, Maldoror adota suas origens étnicas - seu pai é natural da Ilha Marie Galante, do Arquipélago de Guadalupe, nas Antilhas Francesas e envolve-se na luta de libertação de Angola, junto ao esposo, Mário Pinto de Andrade, à altura secretário dos negócios estrangeiros do MPLA.
} 
verdadeira de Domingos Xavier, e rodados fora de Angola, por conta da guerra, ${ }^{3}$ com a colaboração do MPLA e com atores amadores.

Em entrevista concedida a Pedro Cardoso, Maldoror explica que decidiu filmar as lutas pela independência após frequentar a Academia de Cinema de Moscovo, com bolsa da URSS, e conhecer Mário Pinto de Andrade, que a pôs em contato com aquela realidade. "Quando voltei [para a França] de Moscovo, falava-se imenso da guerra do Vietname, mas nunca das lutas africanas. Então pensei 'vou fazer um filme'”. Naquela altura, Luandino Vieira começava a ser conhecido em França e isso provavelmente facilitou a obtenção de subsídios para a realização dos filmes. Além disso, o governo e as instituições francesas financiavam esse tipo de projeto "porque os filmes não eram sobre colónias deles" (NOVO JORNAL, 2008, p. 14-15).

Enquanto o curta Monangambé é um filme de cunho universalizante, tratando de modo abrangente e simbólico questões como a tortura, a incompreensão linguística e a solidão, o longa-metragem Sambizanga documenta ficcionalmente momentos preliminares e fatos locais que culminaram no início da luta armada contra o Império Português em Angola. Por isso, será a partir dele que discutiremos o papel do cinema "enquanto documento histórico e como discurso sobre a história" (MONTEIRO, 2004, p. 7), ferramenta de divulgação de ideologias, mecanismo de denúncia e estratégia na luta contra o esquecimento.

\section{Memória do passado como relato do presente}

A diegese de Sambizanga segue de muito perto a fábula da novela de Luandino Vieira. Domingos Xavier, um tratorista das obras de construção da barragem de Cambembe, ${ }^{4}$ é violentamente arrastado pela PIDE e detido na prisão nova do distrito de Sambizanga, em Luanda, em dezembro de 1960. Em torno de sua prisão move-se uma rede de personagens: sua esposa Maria e o bebê Sebastião, filho do casal, que enfrentam uma difícil viagem a fim de descobrir seu paradeiro; velho Petelo e miúdo Zito, moradores do musseque mais próximo da prisão, que acompanham e divulgam o caso do preso; Mussunda, Xico e Miguel, partidários do MPLA, que procuram descobrir a identidade do preso e retomar o contato com o grupo do Cambembe; e ainda outros personagens que se

\footnotetext{
${ }^{3}$ Manangambé foi filmado na Argélia e Sambizanga no Congo-Brazzaville.

${ }^{4}$ Localizada a cerca de $200 \mathrm{~km}$ a sudoeste de Luanda.
} 
sensibilizam com o caso, como sá Tété e sá Zefa. A vida de verdade de Domingos Xavier começa quando ele se torna um herói nacional, pois "prefere a morte a denunciar seu contacto político mais próximo, o engenheiro Silvestre, como o autor, um branco que se reivindicava angolano" (VENÂNCIO, 1992, p. 26).

Luandino Vieira assina "10 de Novembro, 1961" como data de escrita da novela, e deixa implícito ao leitor compatriota e contemporâneo que o caso fíctício narrado representa a série de prisões violentas, torturas e assassinatos empreendidos pela PIDE no ano anterior e que motivaram a invasão da Casa de Reclusão Militar de Luanda pelo MPLA, episódio que, para o Partido, marca oficialmente o início da luta armada pela libertação de Angola, em 4 de fevereiro de 1961. O próprio Luandino Vieira esteve em situação semelhante, quando preso em 1959. Sua novela surge como um instrumento de denúncia e combate à opressão do sistema colonial e documento de divulgação dos princípios políticos do MPLA. Meses depois da circulação do livro em fotocópias - a publicação só ocorreu em 1971, em Paris (no ano anterior às filmagens do filme) -, o autor volta a ser preso e é condenado a 14 anos de prisão.

Ao recuperar o episódio histórico cerca de dez anos depois, Maldoror acaba por mostrar o desenvolvimento de uma consciência política forte e uma vontade de mudança em Angola, encontrando em A vida verdadeira de Domingos Xavier a possibilidade de captar um momento particular da história das lutas de libertação africanas; matéria para criar um filme capaz de educar os ocidentais do que estava acontecendo em África; e uma ótima deixa para contar a história de uma revolução a partir de um ponto de vista geralmente negligenciado, a perspectiva de uma mulher apanhada em uma situação que ela não entende (DEMBROW, 2000).

Maria, a esposa de Domingos, acaba por ocupar o foco principal do filme, em cena mais da metade da película. Além disso, as angustiantes cenas em que Domingos é torturado evidenciam o esforço de retratar as passagens homólogas do livro o mais realisticamente possível, de maneira a explicitar o ódio racial e os abusos de poder. A meu ver, entretanto, a escolha mais significativa do processo de transposição audiovisual da obra literária diz respeito a uma alteração ligada ao modo de contar. Maldoror e seus corroteiristas $^{5}$ optam por narrar fatos da novela em sua ordem cronológica, segundo princípios de causa, efeitos e consequências.

\footnotetext{
${ }^{5} \mathrm{O}$ escritor Maurice Pons, o cineasta Claude Agostini e Mário Pinto de Andrade.
} 


\section{Tempo e espaço da narrativa: inversão dos ziguezagues}

Os dez capítulos da novela (dez, como os cantos d'Os Lusíadas!) circunscrevem os três últimos dias de vida de Domingos. Os acontecimentos narrados nos quatro primeiros capítulos ocorrem durante o dia da chegada de Domingos à prisão da PIDE, uma quinta-feira. Do quinto ao oitavo capítulo, o dia seguinte, sexta-feira. Os dois últimos capítulos se passam no terceiro dia, sábado. A cada capítulo o foco narrativo é ajustado à perspectiva de um personagem, ou um grupo da rede de personagens, fazendo com que o tempo da narração avance ou retroceda segundo as experiências vividas por cada um deles naqueles três dias, num grande painel, com diferentes vozes.

No primeiro capítulo acompanhamos a chegada do preso na perspectiva de miúdo Zito e velho Petelo e seus esforços para divulgar o fato, repassando os detalhes para seu parente próximo, de participação política, o Xico. No segundo capítulo narra-se um enquanto isso na prisão, o que pensa e sente Domingos Xavier. No terceiro capítulo, o leitor passa o fim daquele dia em companhia de Maria, que acaba de chegar ao Sambizanga. No quarto capítulo, mesma noite, Xico fala a Miguel da chegada do preso. No quinto capítulo, amanhece na prisão Domingos Xavier, que passa por interrogatório. No sexto capítulo, àquelas mesmas horas, Maria sai à procura de Domingos. No sétimo capítulo, mesma manhã, Miguel chega à represa procurando por Sousinha e toma novas informações sobre o preso do dia anterior. No oitavo capítulo, fim de tarde daquele segundo dia, Domingos passa por novo interrogatório, do qual sai moribundo; naquela mesma noite acaba morrendo. No nono capítulo, já no fim da tarde de sábado, Maria vai procurar novamente por Domingos, e acaba por adivinhar, pelo tratamento que lhe dão os cipaios, que seu marido havia morrido; sua história se entrecruza com a de miúdo Zito e velho Petelo, que a consolam. No décimo capítulo, noite de sábado, há uma festa organizada pelo MPLA com o fim de reaproximar os membros e amigos do partido e, no clima de confraternização, reanimá-los para a luta diária contra as prisões da PIDE; miúdo Zito e velho Petelo vêm dizer a Xico da morte do preso, ele os leva a Mussunda, que torna pública a história do mártir, quem sabe "ressuscitado" pelas palavras de Mussunda já na madrugada de domingo, um domingo de Páscoa angolano. A vida verdadeira de Domingos Xavier é, pois, "uma narrativa bruxuleante no tempo, indo e vindo pela cronologia dos acontecimentos conforme o narrador se desloca entre os grupos de personagens que distinguimos ao longo do texto" (DAVID, 2006, p. 85). 
A partir desses eventos, Luandino Vieira se vale de vários recursos de construção temporal para ampliar a história para além daqueles três dias. Há analepses em vários pontos, numa movimentação temporal marcada pela ruptura da continuidade do tempo. Através das digressões de miúdo Zito conhecemos o interesse de velho Petelo pelas prisões da PIDE. Ao se avizinhar de Xico, o narrador freia o desenrolar dos fatos para contar como se deu sua aproximação com o partido, introduzindo o personagem Mussunda e marcando sua importância não apenas na mudança de vida de Xico, mas de muitos outros jovens angolanos. Os pensamentos de Domingos na prisão são uma série de flashbacks intercalados dos motivos que o levaram ali; a partir dessas lembranças conhecemos os personagens Sousinha e engenheiro Silvestre, que haveriam de lutar pela libertação de Angola. Lembremos que alguns desses personagens, como Mussunda e Sousinha, são figuras reais, personalidades históricas. Através da insônia de Maria, narrase sua longa viagem da represa até o musseque, as dificuldades de sua busca por notícias do marido e momentos particulares da vida diária do casal, reveladores do caráter honesto e pacífico de Domingos. O encontro de Miguel com Mussunda também é narrado em flashback enquanto Miguel está a caminho da aldeia de Sousinha.

A montagem do filme, diferentemente, é realizada no sentido de linearizar os principais fatos desta história, por meio da "narração progressiva de eventos consecutivos" (MENDILOW, 1972, p. 183). Tudo se passa em ordem cronológica, a partir das conversas de Domingos com Sousinha - motivo da prisão - e os fatos simultâneos são salientados pela montagem paralela. Por exemplo, na noite em que Domingos é capturado, o que na lógica temporal da novela teria se dado na quinta-feira, mostra-se ora o sofrimento de Domingos no interior da caminhonete azul, ora a angústia de Maria, amparada pelas vizinhas no interior de sua cubata. As imagens dessas duas cenas seguem num vai e vem de planos distantes espacialmente, mas próximos temporalmente por vários minutos do filme (SAMBIZANGA, 1972, 15:29-20:23). Desse modo, põem-se em cena os episódios vividos pelos diferentes personagens conforme a ordem lógica de ocorrência dos fatos, cuja duração em dias não é nitidamente acentuada.

Domingos e Sousinha conversam durante o dia de trabalho. Domingos, após o trabalho, passa o fim de tarde com a família. Domingos é capturado no início da noite. Na cidade, pela manhã, miúdo Zito observa a chegada do preso, avisa velho Petelo e o acompanha até o correio para informar Xico. Enquanto isso, Maria sai da aldeia em direção ao posto da Administração, realizando uma caminhada longa e difícil. Àquelas 
horas, na cidade, Xico conta a Miguel o caso do preso, além de reencontrar a namorada Bebiana. Enquanto isso, Maria continua sua jornada, chega ao posto e, sem achar Domingos, pega um machimbombo para a cidade. Domingos na prisão, na mesma hora, conversa com outros presos. Era já noite quando Maria chega à casa de sá Tété, num musseque da cidade. Na manhã seguinte, Maria sai à procura de Domingos pelos postos policiais. Chega a passar por miúdo Zito. É escorraçada pela PIDE. Domingos passa outra noite na prisão. Miguel viaja até o Bairro Operário para contar o caso do preso a Mussunda. Pouco depois, Domingos é duramente interrogado pela PIDE. Maria continua procurando por ele em outros postos policiais. Miguel, na aldeia, conversa com sá Zefa a respeito de Sousinha e Domingos. Domingos passa por novo interrogatório. Maria volta à PIDE. Domingos é, mais tarde, jogado moribundo junto a outros presos, acaba por morrer. No dia seguinte, Maria sai de dentro da prisão chorando muito. Ao vê-la, miúdo Zito corre a avisar velho Petelo. Um grupo de mulheres do musseque ampara a recente viúva. À noite, faz-se a festa do MPLA. O engenheiro Silvestre está presente. Durante a festa, Mussunda é avisado por Xico, miúdo Zito e velho Petelo da morte do preso. Torna público o caso da morte daquele mártir angolano. Numa manhã, Mussunda e Miguel reúnem-se com Sousinha na obra da represa. Decidem ali organizar o movimento armado para libertar os presos políticos. Como o público-alvo do filme não conhece o fato histórico é preciso pô-lo em cena, explicar o 4 de fevereiro de 1961, momento da história de Angola em que a maré virou.

Como vimos, na novela, a partir de um eixo espacial fixo ziguezagueamos por vários tempos, enquanto no filme o eixo fixo é temporal e dele acessamos, em ziguezague, vários espaços. Desse modo, o filme reforça sua estética documental, sua busca pelas verdades da história inseridas naquela ficção, num claro intuito militante de mostrar uma realidade marginalizada ao resto do mundo. Fixar um momento importante das lutas de libertação em África e dar a ver uma África de pessoas bonitas, corajosas e solidárias. Por conta disso, Maldoror abre mão de narrar os acontecimentos do passado descritos ao longo da novela, exceto, evidentemente, os fatos ocorridos no dia acrescentado: aquele em que se deu a captura de Domingos. Entretanto, um episódio contado em flashback se mostra particularmente importante à cineasta, que acaba por encaixá-lo aos fatos do presente: a lição de Mussunda sobre ricos e pobres.

\section{A cena síntese de um posicionamento político-ideológico}


Na cena da lição de Mussunda sobre ricos e pobres conflui o posicionamento político-ideológico que aproxima escritor e cineasta. É um momento panfletário do livro que só teria condições de se manter inalterado num filme realizado no seio dos mesmos ideais comunistas. No quarto capítulo, o narrador encena uma antiga conversa entre o alfaiate Mussunda e um Xico mais jovem, o diálogo que fez com que na cabeça de Xico Kafundanga não tivesse hoje só mais brilhantina.

E mais tarde, num dia de grande chuva de Abril, amigo Mussunda tinha
falado umas conversas que lhe abriram os olhos: mostrou que não havia
branco, nem preto, nem mulato, mas só pobre e rico, e que rico é
inimigo do pobre porque quer ele sempre pobre. Aí Xico tinha ficado
admirado, refilara com Mussunda - como então, se os ricos dão
trabalho, se os ricos dão o dinheiro, se os ricos dão a esmola nos pobres,
se não havia rico, pobre não tinha trabalho! O alfaiate riu muito na cara
do rapaz. Mas depois lhe explicou muitas coisas, como o rico dá de
maneira que pobre é sempre pobre e trabalha para ele ser sempre rico,
se não havia rico não havia pobre, todo mundo era igual. Pois é, mais
então se dinheiro de rico fica quieto, dá mais dinheiro? Não pode! Só
com o trabalho do pobre, mano Xico, é que o dinheiro dá mais dinheiro
para o rico ficar mais rico, e o pobre? Sukua! Sempre na mesma!
(VIEIRA, 198?, p. 37).

Enquanto a fala de Xico é muito bem pontuada, através de um travessão, a fala de Mussunda se mistura à voz do narrador, que compactua com ela. $\mathrm{O}$ uso do discurso indireto-livre como recurso expressivo, além de potencializar a fluência e ritmo da passagem, garante a sobreposição das vozes de Mussunda, do narrador e do autor implícito. Trata-se de um pensamento compartilhado, de uma lição a ser passada ao leitor, de uma maneira de ver o mundo: se a dicotomia rico e pobre for quebrada, ninguém mais estará preocupado em distinguir as pessoas por seus traços raciais.

Mais adiante, no sétimo capítulo, Miguel relembra seu encontro com Mussunda na noite anterior, depois que o companheiro se despediu dos estudantes com os quais conversava. Esse novo episódio, rememorado na noite de quinta-feira, é mostrado no filme como fato do presente, simultâneo ao segundo dia de Domingos na prisão. Maldoror aproveita a sugestão dessa conversa de Mussunda com estudantes para introduzir, por meio dela, a lição sobre ricos e pobres. Ao jovem e inexperiente estudante anônimo cabe as dúvidas de Xico. O ator amador que interpreta o alfaiate (Lopes Rodrigues) reproduz com convicção a referida passagem da novela, sua expressão é grave e amigável, a atmosfera em torno dele é de sabedoria e desinteresse por ganhos pessoais. 
A um plano detalhe da mão de Mussunda cortando o couro segue um plano médio dos estudantes a anotar o que lhes é dito. Valoriza-se o olhar atento dos estudantes e a serenidade do alfaiate-professor. Enquanto fala, Mussunda continua a trabalhar. Suas palavras ecoam pela oficina e atingem seus funcionários-aprendizes. A lição é também para eles. Para todo o povo, para a nova e a velha geração de trabalhadores - um de seus aprendizes é pouco mais velho que miúdo Zito e o outro pouco mais jovem que velho Petelo - que precisam aprender um trabalho artesanal, uma profissão, um ofício, e compreender a lógica das indústrias capitalistas para serem capazes de apartar-se delas.

A proposta da novela, que se procura manter no filme, é traduzir o querer manifesto do povo, dar forma a seu passado, descrever o seu presente, delimitar seus sonhos para o futuro. "Para os homens intelectuais colonizados a cultura aparece como campo de batalha privilegiado, defendem com paixão a existência de uma cultura nacional" (FANON, 1968, p. 173). São obras politicamente empenhadas, que refletem uma estética e uma ideologia comum que podemos chamar, genericamente, de neorrealistas.

\section{Recuperação de uma reminiscência}

O intuito de representar o real e de documentar a história presente em ambas as obras acaba por marcar, como vimos, as particularidades da trama de cada uma delas. $\mathrm{Na}$ comparação entre este filme e este livro, é o ponto de ligação fundamental entre literatura e cinema, o modo semelhante como manipulam o "fluxo temporal", próprio da épica, narrativo em suma (BELLO, 2008, p. 76), o que os distingue. A presentificação do que já é memória, seja pela arte ou pela ciência, é impossível e sequer desejável. "A verdadeira imagem do passado perpassa, veloz. O passado só se deixa fixar, como imagem que lampeja irreversivelmente, no momento em que é reconhecido" (BENJAMIN, 1996, p. 224). Dar a ver, e a ler, é segurar por algum tempo esse relâmpago, e por meio disso convidar o espectador e o leitor à reflexão, de modo a estimular o pensamento.

Nesse ponto, o artista neorrealista acaba por "afirmar a sua condição de entidade socialmente posicionada e, por isso, sintonizada com os problemas sociais, políticos e econômicos do seu tempo" (REIS, 1981, p. 16). Seu intuito enquanto artista, e através da obra de arte articulada à história, é levar o público a refletir sobre a realidade, a contestar paradigmas. Para isso, é preciso evidenciar os problemas subjacentes a certas estruturas sociais, enfatizar o objeto de denúncia, escancará-lo. Desse modo, é irrelevante julgar 
uma obra neorrealista pelo teor de realidade presente nela ou o grau de fidedignidade que mantém com o momento histórico retratado.

\begin{abstract}
A liberdade, mesmo dentro da orientação documentária, é o quinhão da fantasia, que às vezes precisa modificar a ordem do mundo justamente para torná-la mais expressiva; de tal maneira que o sentimento da verdade se constitui no leitor graças a essa traição metódica (CANDIDO, 2008, p. 24).
\end{abstract}

Dentre as artes neorrealistas, o seu cinema merece uma atenção especial, porque é uma arte-espetáculo capaz de chegar a muitas pessoas e porque, ao recortar e manipular imagens capturadas do próprio mundo, tem um apelo de verdade mais evidente e perigoso. Maldoror quer dar a ver a realidade silenciada de África ao restante do globo e para isso transforma pessoas e espaços africanos reais em atores e palcos de uma encenação da novela de Luandino Vieira, cuja fábula articula ficcionalmente fatos históricos. Ao apropriar-se dessa reminiscência, "tal como ela relampeja no momento de um perigo" (BENJAMIN, p. 224), e ao apresentar uma ressignificação de um marco do passado frente às necessidades do presente, a cineasta acaba por criar um mundo extremamente maniqueísta, em que todos os elementos do sistema capitalista são representativos de um mal e todos os elementos do sistema comunista são reveladores de um bem.

Apesar de a verdade ser inatingível e só ser possível pensar o mundo por meio dos princípios e valores que escolhemos dentre aqueles a que temos acesso, A vida verdadeira de Domingos Xavier e Sambizanga são obras com o "dom de despertar no passado as centelhas da esperança” (BENJAMIN, p. 224). A tortura e morte de Domingos Xavier, e de muitos como ele, faz com que continuemos a pensar nos episódios obscuros da história e paremos para refletir sobre o que queremos para o mundo atual. Os testemunhos dessas violências não podem ser esquecidos e é preciso que todas as pessoas do planeta as reprovem abertamente para que elas parem de acontecer, em 1960, em 1970 e ainda hoje.

\title{
Referências bibliográficas
}

BELLO, Maria do Rosário Lupi. Narrativa literária e narrativa fílmica: o caso de Amor de Perdição. 2. ed. Coimbra: Fundação Calouste Gulbenkian e Fundação para a Ciência e a Tecnologia (FCG-FCT), 2008. (Textos Universitários de Ciências Sociais e Humanas.)

BENJAMIN, Walter. Sobre o conceito da história. In: Magia e técnica, arte e política: ensaios sobre literatura e história da cultura. Trad. Sérgio Paulo Rouanet. 7. ed. 10. reimp. São Paulo: Brasiliense, 1996, p. 222-232. (Obras escolhidas, vol. 1.) 
CANDIDO, Antonio. Literatura e sociedade. 10. ed. Rio de Janeiro: Ouro sobre Azul, 2008.

DAVID, Debora Leite. Dois cárceres, uma certeza: a morte. Um estudo comparado entre $A$ vida verdadeira de Domingos Xavier de Luandino Vieira e Memórias do cárcere de Graciliano Ramos. São Paulo, 2006. 157 f. Dissertação (Mestrado em Letras) - Faculdade de Filosofia, Letras e Ciências Humanas, Universidade de São Paulo.

DEMBROW, Michael. Sambizanga and Sarah Maldoror. In: Studies in African Film, Lewis \& Clark College, Summer Session II, 2000. Material de curso, artigo on-line. Disponível em: http://spot.pcc.edu/ mdembrow/sambizanga.htm. Acesso em 27 abr. 2013.

FANON, Frantz. Os condenados da terra. Prefácio de Jean-Paul Sartre. Trad. José Laurêncio de Melo. [Rio de Janeiro]: Civilização Brasileira, [1968].

FERRO, Marc. Cinema e história. Trad. Flávia Nascimento. Rio de Janeiro: Paz e Terra, 1992.

MENDILOW, Adam Abraham. O tempo e o romance. Trad. Flávio Wolf. Porto Alegre: Globo, 1972.

MONTEIRO, Miguel (org.). Cinema \& História. 6 a 10 de outubro de 2003. Lisboa: Centro de História da Universidade de Lisboa, 2004.

NOVO JORNAL. Entrevista. Sarah Maldoror, cineasta. "Em nome da moral fazem-se guerras". Por Pedro Cardoso. Luanda, p. 14-16, 28 nov. 2008.

REIS, Carlos. Do realismo ao neo-realismo. In: Textos teóricos do neo-realismo português. Lisboa: Seara Nova, 1981, p. 13-41.

SAMBIZANGA. Direção: Sarah Maldoror. Angola; França: Isabelle Films, 1972. Drama, 102 min., $35 \mathrm{~mm}$, eastmancolor. DVD (New Yorker films release).

VENÂNCIO, José Carlos. Literatura e poder na África lusófona. Lisboa: Instituto de Cultura e Língua Portuguesa do Ministério da Educação, 1992.

VIEIRA, José Luandino. A vida verdadeira de Domingos Xavier. São Paulo: Ática, [198?]. Escrito em 1961. Primeira edição de 1971. 